\title{
Approach for external measurements of the heat transfer coefficient (U-value) of building envelope components using UAV based infrared thermography
}

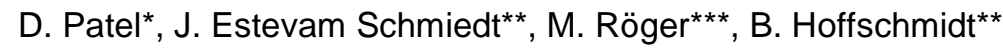 \\ *German Aerospace Center (DLR), Institute of Solar Research, Karl-Heinz-Beckurts-Str. 13, 52428, Köln, \\ Germany, dhruvkumar.patel@dlr.de \\ **German Aerospace Center (DLR), Institute of Solar Research, Linder Höhe, 51147, Köln, Germany \\ ***German Aerospace Center (DLR), Institute of Solar Research, Plataforma Solar de Almería, 04200, \\ Tabernas, Spain
}

\begin{abstract}
A high share of heating energy consumption by buildings is due to poorly insulated building envelopes. Identification of poorly insulated building envelopes is still a challenge. Nowadays, remote sensing equipment has become increasingly inexpensive and accessible. This paper evaluates the potential of using unmanned aerial vehicles (UAVs) carried equipment for quantitative analysis of the thermal properties of building envelopes. A comprehensive uncertainty analysis of the U-value measurement is conducted. In the uncertainty budget, an error in temperature measurement with IR camera contributes the largest share of uncertainty. Additionally, IRT measurements are compared with the heat flux meter (HFM) method.
\end{abstract}

\section{Introduction}

In Germany, heating energy accounts for $27 \%$ of the total energy consumption. This makes it the second largest share of energy usage after mechanical energy (39\%) [1]. In order to fulfil the German government's objective to reduce the primary energy demand of buildings by about $80 \%$ (with respect to 2008) until 2050, existing buildings should be analysed, so that the poorly insulated building envelopes can be identified and refurbished [2]. The identification of poorly insulated building envelopes is a challenging task. Intrusive measurement methods like HFM and the Temperature Based Method (TBM) [3] are time-consuming and expensive - in particular if analyses are to be performed for larger areas. Handheld infrared thermography (IRT) is frequently used to determine the thermal characteristics of a building. However, in most cases it is used as a qualitative approach. Studies about quantitative thermography to determine U-values for walls exist but they only consider measurements from inside of the building to avoid challenges like high wind speed or large variations in the environmental radiation on the test surface. Recent work shows that the deviation in U-value lies within 3-4\% for single-leaf and multi-leaf walls using IRT from inside of the building [4]. Furthermore, the research presented for outside in-situ U-value measurement with Infrared Thermovision Technique (ITT) shows deviation from 8.9$39.8 \%$ for different wall structures, compared with HFM method [5].

To examine large numbers of buildings in a non-intrusive way, aerial remote sensing technology has a great potential to provide reliable information with less investment of time and money [6]. In recent time, UAVs are already being used for the qualitative analysis of the building surfaces [7]. In this paper our goal is to investigate the potential of IRT using UAVs for quantitative measurements of U-values for building envelopes. To achieve this goal, we initially check the reliability of external IRT measurements. Nowadays, the UAVs have become more advanced and are capable of taking the images in a stable condition. It allows us to compare the images taken with the stationary handheld and airborne cameras for UAVs. Furthermore, an uncertainty and sensitivity analysis are also presented in the paper to investigate the most influencing parameters. The U-value measured with external IRT is also compared with HFM method to check the deviation.

The presented work is part of the ongoing research activities to make remote sensing techniques applicable for energetic analyses of buildings. Our goal is to develop a tool box of measurement and analysis methods to determine the thermal properties of building envelopes quickly and accurately. Thus, single building or whole districts may be examined in short time to obtain crucial information for the development of refurbishment strategies or about loads of the energy networks.

\section{U-value measurement approaches}

The estimation of the energy performance of existing buildings requires the knowledge of the overall U-value of the walls. The U-value of a building envelope can be defined as described in Eq. [1], which equals the heat flow passes through the building envelope divided by the difference of inside and outside air temperature near the envelope. The $U$ value can be calculated from the thermal conductivity and thickness of each material that constitutes the wall structure. U-values can also be obtained experimentally through the ISO 9869-1:2014 recommended HFM method [8]. A few years ago, an alternative approach based on IRT has been proposed for in situ measurements. The main advantage is that it is a non-destructive method and large areas can be analysed in short time which saves both time and cost. IRT is normally 
used from inside of the building to measure the U-value of the building envelop in order to reduce the errors from unknown ambient reflection on the wall surface and a varying convective heat transfer coefficient. In the following chapter, brief introduction about different approaches are presented.

\subsection{U-value measurement with HFM}

The measurement setup consists of mainly two types of sensors. A heat flux sensor is directly mounted on the wall surface inside of the room where the temperature is more stable. Two temperature sensors are mounted outside and inside of the room to measure the ambient air temperatures. Both temperature sensor heads should be protected from thermal radiation, wind, snow, rain and direct solar radiation. A minimum temperature difference of $10-15 K$ between indoor and outdoor environment should be maintained to get a measurable heat flow through walls. The HFM consists of monitoring the heat flux rate passing through the façade with heat flux sensor and the indoor and outdoor environmental temperatures to obtain the thermal transmittance. However, this method presents some limitations, e.g., it can only measure at a specific point on the wall. Therefore, it fails in providing the results for non-homogeneous building elements. Moreover, as explained in ISO 9869-1:2014, the measurement period requires at least 72 hours up to 7 days [8].

\subsection{U-value measurement with IRT}

IRT is a contactless method based on radiation emitted from an object's surface. Traditionally, IRT has been used only for detecting the leaks and irregularities in the building envelopes qualitatively. In recent years, quantitative IRT methods have also been adapted to determine the thermal characteristics of the building envelopes $[4,9,10]$. IRT provides the U-value measurement of a building envelope in a span of few hours and also suitable for inhomogeneous walls. Eqs. (1) and (2) are used to calculate the U-value of the building envelope.

$$
\begin{aligned}
& U=\frac{\dot{q}}{\left(T_{\text {in }}-T_{\text {out }}\right)}=\frac{\dot{q}_{\text {rad }}+\dot{q}_{\text {conv }}}{\left(T_{\text {in,air }}-T_{\text {out }, \text { air }}\right)} \\
& =\frac{\varepsilon_{\text {wall }} \cdot \sigma \cdot\left(T_{\text {wall }}^{4}-T_{\text {reflected,outside }}^{4}\right)+h_{c, \text { outside }} \cdot\left(T_{\text {wall }}-T_{\text {out }, \text { air }}\right)}{\left(T_{\text {in,air }}-T_{\text {out }, \text { air }}\right)},
\end{aligned}
$$

where $U$ denotes heat transfer coefficient; $\varepsilon_{\text {wall }}$ is the thermal emissivity of wall; $\sigma$ is Stefan-Boltzmann's constant; $T_{\text {reflected,outside }}$ is an averaged outside reflected ambient temperature; $T_{\text {wall }}$ is the surface temperature of wall; $\dot{q}$ is the specific heat flux through the building envelope including the specific heat flux by radiation $\dot{q}_{\text {rad }}$ and the specific heat flux by convection $\dot{q}_{c o n v} ; h_{c, \text { outside }}$ is the convective heat transfer coefficient of the outside air; $T_{i n \text {,air }}$ is the air temperature near the wall from inside the building and $T_{\text {out,air }}$ is the outdoor air temperature near the wall.

The radiation coming from an object consists of three different sources; the emission of the target object, the emission of the surroundings which are reflected by the object and the emission of the atmosphere. In this method we make the assumption that the object's surface behaves like an opaque grey body which emits the same constant fraction of radiation in each wavelength and each direction. The emissivity is neither dependent on observing angle nor the wavelength range of IR camera [11]. If the distance of an object and camera is small, it is possible to consider the atmospheric transmission $\tau_{a t m}$ value as one. Therefore, the radiation coming from atmosphere becomes zero. As per the Stefan-Boltzmann's law, the radiation energy generated from a black body $W_{b}$ is described in the Eq. (3). The radiosity $(W)$ of the grey opaque object can be expressed as Eq. (4) [12].

$$
\begin{aligned}
& W_{b}=\sigma \cdot\left(T_{b}^{4}\right) \\
& W=\varepsilon_{\text {wall }} \cdot \sigma \cdot\left(T_{\text {wall }}^{4}\right)+\left(1-\varepsilon_{\text {wall }}\right) \cdot \sigma \cdot\left(T_{\text {reflected }}^{4}\right) \\
& T_{\text {wall }}=\sqrt[4]{\frac{W-\left(1-\varepsilon_{\text {wall }}\right) * \sigma *\left(T_{\text {reflected,outside }}^{4}\right)}{\varepsilon_{\text {wall }} * \sigma}}
\end{aligned}
$$

Using Eq. (5), the wall temperature $T_{\text {wall }}$ can be calculated with the value of emissivity, ambient reflected temperature and radiation coming from the wall surface. The value of $W$ in the IR camera readings is presented as digital number stored in a matrix in the raw file. This digital number is then post-processed with calibration data in order to get the temperature value. An emissivity of the wall can either be measured or taken from standard emissivity tables. The ambient reflected temperature is determined using crumpled aluminium foil fixed on the wall surface, in the field of view of the infrared image, as described in the standard [13]. The ambient reflected temperature is calculated by giving an emissivity of one to the aluminium foil area and averaging the evaluated temperature over the foil area.

IRT has been used to measure the U-values from the inside of the building due to several benefits. Firstly, IRT from inside of the building provides more controlled environment with slower and less significant climate fluctuations. 
Secondly, the thermal status of the surrounding objects can be easily measured in order to calculate the thermal reflections from the surrounding objects on the test object. Finally, the internal convective heat transfer is not fluctuating significantly due to the negligible wind speed inside the room. Therefore, in recent literature this method is chosen widely to measure the U-value of building envelopes [4,14].

Unlike the HFM method there is no standardized procedure to determine U-values of building envelope components from the outside of the building with IRT, yet. On the other hand, one standard is now available to measure the U-value of the building elements from inside [15]. In this paper, a possible approach to measure U-values with IRT is presented. Aerial thermography with UAVs is becoming more popular in recent years, since the technology is becoming increasingly cheap and user friendly. Apart from that, UAVs can cover larger areas and capture images at different angles in short time which is difficult with handheld thermography. In this paper, we assume UAVs with 1 to $5 \mathrm{~kg}$ of total lifting capacity and 20-25 minutes of flying time, because this class is widely commercially available, user friendly and portable. Such a UAV can be equipped with a normal camera, an IR camera to take images of the test object and sensors to measure air-temperature and humidity.

Coming back to the Eq. (2), the convective heat transfer coefficient is influenced by several factors such as, geometry of the building and building surroundings, position of the building envelope, roughness of the building surface, speed and direction of the wind, local air flow patterns and surface to air temperature differences [16]. Convective heat exchange for an external building surface is generally calculated based on the knowledge of the convective heat transfer coefficient $\left(h_{c, \text { outside }}\right)$. The convective heat transfer coefficient plays an important role for the accurate evaluation of heat flow from building envelopes. There are various methods to obtain values for $h_{c, \text { outside. }}$ In this paper, we have used a model presented by Liu \& Harris [17], see table 1. This model is based on full-scale experiments performed on the façade of a single-storey building in a rural environment partially sheltered by tree belts and nearby buildings. These are the identical situations as the test walls in Jülich.

Table 1. Expression used in the model by Liu \& Harris for $h_{c, \text { outside }}$ based on different wind speed [17].

\begin{tabular}{|l|l|l|l|}
\hline \multirow{2}{*}{$\begin{array}{l}\text { Surface } \\
\text { Orientation }\end{array}$} & \multicolumn{3}{|l|}{ Expression } \\
\cline { 2 - 4 } & $h_{c, \text { outside }}$ and $v_{\text {loc }}($ up to $3 \mathrm{~m} / \mathrm{s})$ & $h_{c, \text { outside }}$ and $v_{R}$ (up to $9 \mathrm{~m} / \mathrm{s}$ ) & $h_{c, \text { outside }}$ and $v_{10}$ (up to $16 \mathrm{~m} / \mathrm{s}$ ) \\
\hline Windward & $6.31 \cdot v_{l o c}+3.32$ & $2.08 \cdot v_{R}+2.97$ & $1.53 \cdot v_{10}+1.43$ \\
\hline Leeward & $5.03 \cdot v_{l o c}+3.19$ & $1.57 \cdot v_{R}+2.64$ & $0.90 \cdot v_{10}+3.28$ \\
\hline
\end{tabular}

\section{U-value measurement results}

To examine the external IRT approach, we have made test measurements at the test wall setup in Jülich, Germany and the input data of the unknown parameters are also taken form the test measurement results. There are three different types of test walls; a light weight concrete wall, reinforced concrete wall and brick masonry wall with inside and outside layers of plaster. For the measurements, the inside area of the walls is heated up in order to achieve the average temperature difference of $10 \mathrm{~K}$ between inside and outside air. The U-value of the measured light weight concrete wall is $1.2\left(\mathrm{~W} / \mathrm{m}^{2} \mathrm{~K}\right)$ as provided by the manufacturer. There are several approaches in the literature to determine the thermal emissivity of an object using infrared sensors $[9,10]$. In this measurement approach, we have used tabled emissivity value of the plaster material with rough surface given in the literature $[18,19]$. The surface temperature of the wall and reflected outside temperature are being measured by the IR camera. It operates in the wavelength range from $7.5 \mu \mathrm{m}$ to $13 \mu \mathrm{m}$ and contains an uncooled microbolometer detector.

\subsection{U-value result with external IRT}

The U-value of the test wall in Jülich is evaluated with IRT method using the microbolometer IR camera similar to the IR cameras used in UAV measurement. We chose the method for $h_{c, \text { outside }}$ based on $v_{\text {loc }}$ in windward surface orientation depending upon the test wall's geometry and wind speed. The inside air temperature is measured with temperature sensor mounted near the wall to be measured. In Fig. 1(a), a photo of the test wall surface can be seen. Here, temperature sensor is used in order to measure the outside air temperature for the HFM method. In Fig. 1(b), an IR image of the test wall surface is presented where the temperature distribution can be seen. The large blue cooler area on the right side of the wall is due to a wooden block mounted inside the wall structure which insulates better than the bricks structure. The small area R1 shows the ambient temperature reflected on the aluminium foil fixed on the wall surface. 


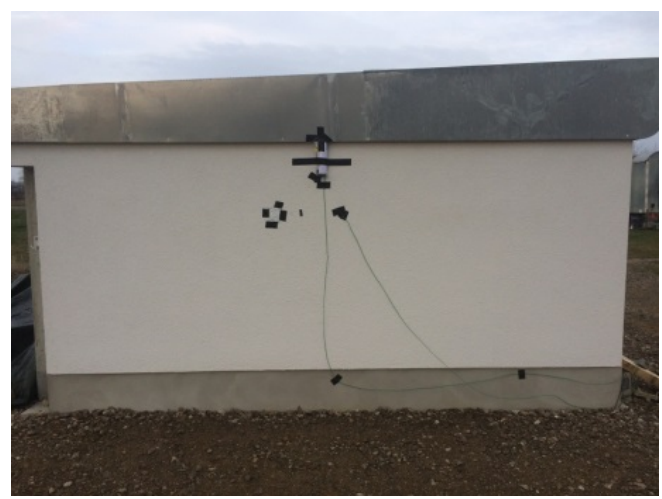

(a)

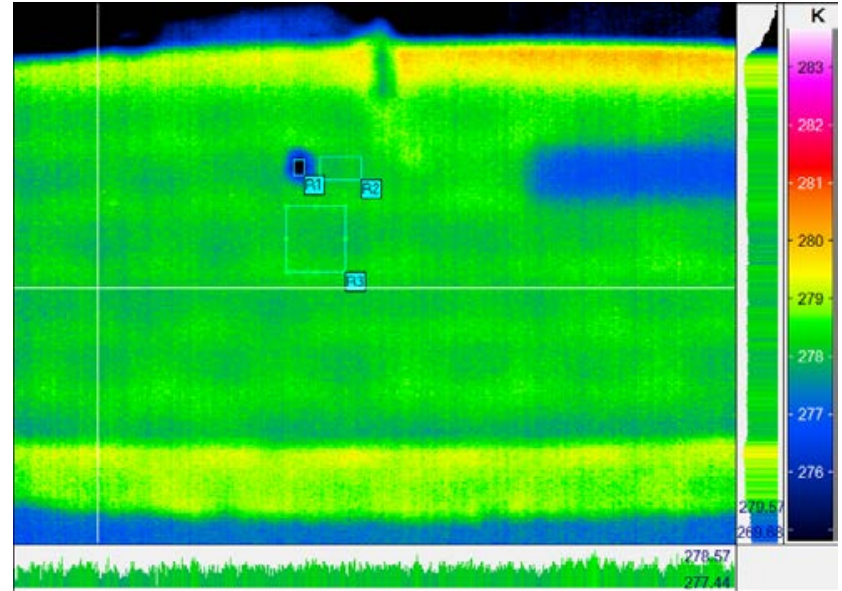

(b)

Fig. 1. Image (a) and IR image (b) of measured wall.

A black tape is pasted in the area R2 as reference for emissivity. The average temperature of an area R3 is considered as a wall temperature of that particular region. The resulting $U$-value can be seen in table 3.

\subsection{U-value result with HFM method}

For the reference measurement, the HFM method is used to calculate the U-value of the wall. In this method, heat flux sensors and air temperature sensors are used. During the construction of the wall, two heat-flux sensors are mounted under the plaster in order to eliminate the direct effects of thermal and solar radiation on the sensors. Apart from that, one flexible heat-flux sensor is mounted inside the room on the wall surface. All three heat-flux sensors provide heat flux values which can be compared and analysed in order to check the error. The measurement has been carried out for 24 hours and the measured $\mathrm{U}$-value of the wall is $1.29\left(\mathrm{~W} / \mathrm{m}^{2} \mathrm{~K}\right)$.

\section{Uncertainty analysis of U-value measurement with IRT}

In the case of infrared measurements from the inside of the building, previous research suggests that the thermal emissivity and reflected ambient temperature are the main sources of uncertainty [14]. In external measurements, it is clear that the boundary conditions are even difficult to control because of the possibly higher wind speed and unknown ambient reflections. Moreover, using a UAV may increase the uncertainties in the measurement due to the use of light weight IR cameras, which are usually less accurate than larger stationary IR cameras. We perform an uncertainty analysis which takes into account measurement uncertainties for all quantities that affect the $U$-value. This analysis gives an estimation of the highest possible accuracy of external IRT based U-value measurements. At the same time, it allows us to identify the most important sources of uncertainty.

To calculate the uncertainty in the U-value, it is important to understand the mathematical models involved in this process [20]. With these models, it is possible to apply the law of propagation of uncertainty from the input to the output. All the variables are considered uncorrelated in this analysis; therefore we use Eq. (6).

$$
u_{C}^{2}(y)=\sum_{i=1}^{N}\left[\frac{\partial f}{\partial x_{i}}\right]^{2} \cdot u^{2}\left(x_{i}\right)
$$

where $x_{i}$ are the estimates of the input variables; $u_{C}(y)$ is the combined standard uncertainty associated to the output variable $y$; and $f$ is the function that correlates input variables $x_{i}$ to output variable $y$. The standard uncertainty of each parameter is measured considering type B uncertainty because there is no statistical error involved in the analysis. Furthermore, a rectangular distribution of possible values is considered for all parameters. 
Table 2. Sensors and their uncertainties used for the different measurements in the U-value determination.

\begin{tabular}{|c|c|c|c|}
\hline Parameters & Sensors & $\begin{array}{l}\text { Half-width of uncertainty } \\
\text { limits }( \pm)\end{array}$ & $\begin{array}{l}\text { Estimated (E) } \\
\text { Calculated (C) } \\
\text { Manufacturer (M) }\end{array}$ \\
\hline Emissivity & Reference table & 0.02 & $E$ \\
\hline Wall surface temperature & IR camera & $1(K)$ & $E$ \\
\hline $\begin{array}{l}\text { Radiation coming from test } \\
\text { object }\end{array}$ & IR camera & 4.25 (grey values) & $\mathrm{C}$ \\
\hline Ambient reflected. temperature & IR camera & $1(K)$ & $E$ \\
\hline Outside air temperature & $\begin{array}{l}\text { Temperature sensor } \\
\text { (NiCr-Ni) }\end{array}$ & $0.5(K)$ & $\mathrm{M}$ \\
\hline Inside air temperature & $\begin{array}{l}\text { Temperature sensor } \\
\text { (NiCr-Ni) }\end{array}$ & $0.5(K)$ & $\mathrm{M}$ \\
\hline Wind velocity & Vane Anemometer & $3 \%(m / s)$ & $\mathrm{M}$ \\
\hline
\end{tabular}

In the GUM Workbench 1.3 software, all the measured parameters are inserted with their half-width of uncertainty limits as shown in table 2. The half-width of uncertainty limits in all the parameters are estimated (E), calculated $(\mathrm{C})$ or provided by manufacturer $(\mathrm{M})$. If an IR camera has an error of $\pm 1 \mathrm{~K}$ in temperature measurement, then this error can be used to calculate the error in $W$ (Radiation coming from test object) using the Eq. [4] by varying the value of $T_{\text {wall }}$ by $1 K$.

Table 3. Uncertainty budget of U-value measurement with IRT produced in GUM Workbench.

\begin{tabular}{|c|c|c|c|c|c|}
\hline \multicolumn{6}{|c|}{ Uncertainty Budget } \\
\hline Quantity & Symbol & Value & $\begin{array}{l}\text { Standard } \\
\text { Uncertainty }\end{array}$ & $\begin{array}{l}\text { Uncertainty } \\
\text { Contribution } \\
\left(\boldsymbol{W} / \boldsymbol{m}^{2} \mathrm{~K}\right)\end{array}$ & $\begin{array}{l}\text { Index } \\
\text { (\%) }\end{array}$ \\
\hline Emissivity & $\varepsilon_{\text {wall }}$ & 0.91 & 0.0115 & -0.016 & 0.1 \\
\hline Sigma $\left(W / m^{2} K^{4}\right)$ & $\sigma$ & $5.6703 e-8$ & & & \\
\hline Wall temperature $(K)$ & $T_{\text {wall }}$ & 278.08 & 0.557 & & \\
\hline $\begin{array}{ll}\text { Ambient } & \text { reflected } \\
\text { temperature }(K) & \end{array}$ & $T_{\text {reflected,outside }}$ & 275.31 & 0.557 & -0.18 & 15.6 \\
\hline $\begin{array}{l}\text { Conv. heat transfer } \\
\text { coefficient }\left(W / m^{2} K\right)\end{array}$ & $h_{c, \text { outside }}$ & 8.36 & 2.08 & 0.026 & 0.4 \\
\hline $\begin{array}{l}\text { Outside air temperature } \\
(K)\end{array}$ & $T_{\text {out }, \text { air }}$ & 277.85 & 0.289 & -0.12 & 7.3 \\
\hline Inside air temperature $(K)$ & $T_{\text {in,air }}$ & 296.05 & 0.289 & -0.012 & 0.0 \\
\hline $\begin{array}{l}\text { Radiation coming from } \\
\text { wall }\left(W / \mathrm{m}^{2}\right)\end{array}$ & $W$ & 337.87 & 2.45 & 0.39 & 76.5 \\
\hline U-value $(W / m$ & & 0.771 & 0.444 & & \\
\hline
\end{tabular}

As shown in table 3, the U-value of the wall, measured with external IRT approach is $0.771\left(\mathrm{~W} / \mathrm{m}^{2} \mathrm{~K}\right)$. Total standard uncertainty in the overall calculation is $0.444\left(\mathrm{~W} / \mathrm{m}^{2} \mathrm{~K}\right)$ which is $57.58 \%$ deviation in the actual U-value. The result shows the large uncertainties present in the external measurement of U-value with IRT. In table 3 , all the parameters involved in the U-value measurement can be seen in the first column and their input values are in third column. The input values are taken from the test measurement at the test wall in Jülich. The wall surface temperature is not measured directly, so the standard uncertainty and index columns are blank. Referring to the index column in uncertainty budget, the highest contribution of $76.5 \%$ is due to the radiation coming from the wall surface. The second highest contribution of $15.6 \%$ comes from the ambient reflected temperature $\left(T_{\text {reflected,outside }}\right)$ which is also measured by an IR camera using the aluminium foil. Hence, an error in the IR camera reading affects both the measurements of radiation coming from object and the ambient reflected temperature. The third highest contribution of $7.3 \%$ comes from the outside air temperature. The emissivity, inside air temperature and wind-velocity contribute less than $0.1 \%$ to the uncertainty budget of this measured test wall.

In previous research [14], it is shown that the emissivity of an object plays the most important role in the U-value measurement with IRT. In contrast, this uncertainty analysis budget concludes that the error in emissivity measurement does not lead to the large error in U-value. As shown in Eq. (7), this occurs because the emittance value cancels out for the underlying case in the dominant radiative term $\dot{q}_{\text {rad }}$ in the derivation of the U-value while using IR techniques. This radiative term is one magnitude higher than the convective in the regarded case. If we introduce Eq. (5) into Eq. (2), we can observe this cancellation. 


$$
U=\frac{\frac{\overbrace{W-\sigma *\left(T_{\text {reflected,outside }}^{4}\right)}^{\text {radiative term }}}{h_{c, \text { outside }} \cdot\left(\sqrt[4]{\frac{W-\left(1-\varepsilon_{\text {wall }}\right) * \sigma *\left(T_{\text {reflected,outside }}^{4}\right)}{\varepsilon_{\text {wall }}^{*} \sigma}}-T_{\text {out,air }}\right)}}{\left(T_{\text {in, air }}-T_{\text {out }, \text { air }}\right)}
$$

Another interesting result is the influence of an inside air temperature, which is also less than $0.1 \%$, as shown in table 3. This supports our aim to measure the U-value from outside of the building. An error of $\pm 2 K$ in inside temperature neither affects much the $U$-value nor does it contribute significantly to the uncertainty index. It enables us to guess an inside temperature in a reasonable range and calculate the U-value without going inside of the building.

To get additional insight of the influence of all the parameters, a sensitivity analysis is carried out using Eq. (2). Here, as a standard case, all the input values are taken from the test measurement presented in table 3 . The standard uncertainty value for each parameter in table 3 is multiplied by the factor of four and the deviation in U-value is calculated using the lower and upper limit of the value. For example, the standard uncertainty in emissivity is 0.0115 , which becomes 0.046 by multiplying with factor of four. Consequently, for the standard case value of 0.91 , the lower limit and upper limit of emissivity becomes 0.86 and 0.95 respectively. Then the deviation in U-value is calculated for three different emissivity values as shown in Fig. 2(a). In all the graphs below, the values on vertical y-axes are varied and the deviation in the $U$-value can be seen on the horizontal x-axes. Likewise Fig. 2(b) shows the influence of convective heat transfer coefficient. In Fig. 2(c), the sensitivity analysis of all the temperature parameters is carried out. Clearly, the wall surface temperature and the ambient reflected temperature have the maximum influence on the $U$-value. Moreover, the outside air temperature also has some noticeable influence and the inside air temperature affects negligibly on the $U$ value.

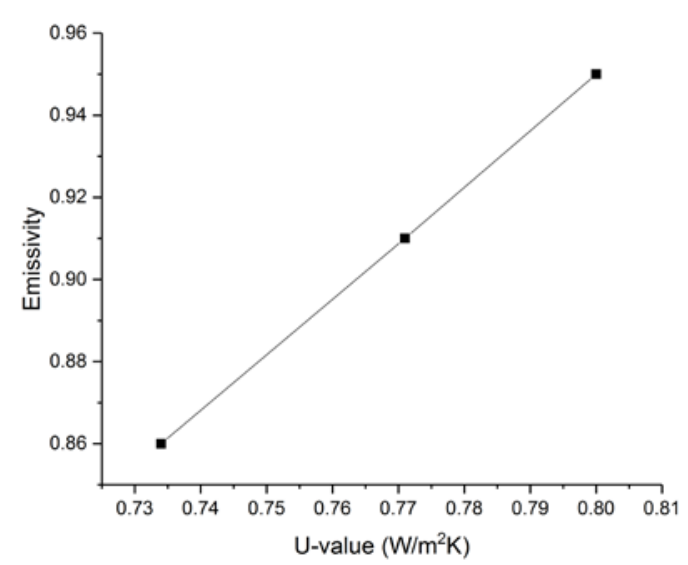

(a)

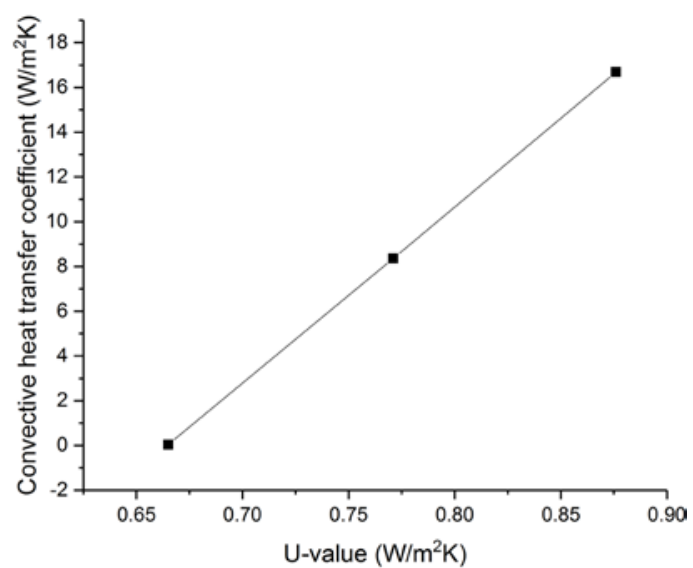

(b)

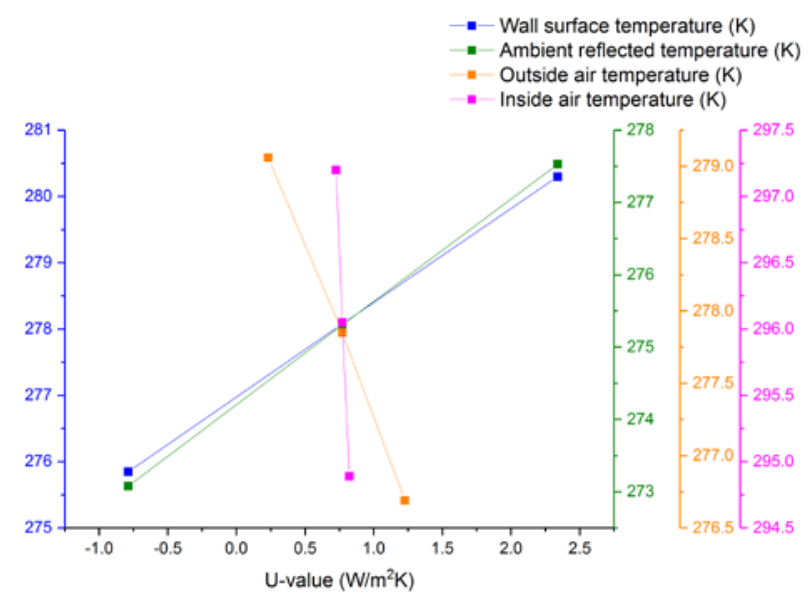

(c)

Fig. 2. Change in U-value (x-axes) by varying emissivity (a), convective heat transfer coefficient (b) and different temperature quantities (c) 


\section{Conclusions}

In this research work, an approach for the U-value measurement from UAVs using IRT is presented. In order to determine the most influencing parameters, a comprehensive uncertainty analysis is conducted which is the main contribution of this work. In the uncertainty budget, the radiosity of the test object and the background reflection on the test object, are the most influencing parameters on the U-value measurement. Both the parameters are measured by an IR camera and contribute $76.5 \%$ and $15.6 \%$ in the uncertainty budget, respectively. The third most influencing parameter is outside air temperature with uncertainty contribution of $7.3 \%$. To measure the external heat transfer coefficient a model by Liu \& Harris is selected depending upon the location and the geometry of the building envelope. The other models need to be investigated in detail to avoid errors from convective heat transfer coefficient. U-value measurement experiment at a test wall in Jülich is conducted using external IRT and the HFM method. The U-value with external IRT resulted in $40.23 \%$ of error compared to HFM measurement. To bring this error to an acceptable level it is important to reduce the errors caused by the IR camera in the first place.

On the other hand, the uncertainty budget concludes that the emissivity and inside room temperature have very small influence on the U-value measurement. Therefore, the emissivity value of building materials can be used from the emissivity tables. A small uncertainty contribution from inside room temperature enables the possibility to develop the complete external measurement procedure with IRT.

UAVs can also be used to measure the background reflected temperature without using an aluminium foil. The IR camera on the UAVs can be rotated in all the direction and it can take multiple images of the background. In the post processing all the IR images can be stitched together and the average temperature of the background can be calculated. This is a proposal for assessing larger districts with UAVs where the use of an aluminium foil on each building is not feasible.

\section{Acknowledgement}

The authors gratefully acknowledge the German Ministry for Economic Affairs and Energy for funding this work in the framework of the Gtom project (03ET1405A).

\section{REFERENCES}

[1] BMWi (2017): Energiedaten: Gesamtausgabe. Bundesministerium für Wirtschaft und Energie.

[2] BMWi (2010): Energiekonzept für eine umweltschonende, zuverlässige und bezahlbare Energieversorgung. Germany

[3] Buunk, Jeroen (2015): greenTEG White Paper_U-value measurement_HFM vs TBM. greenTEG. Available online at greenTEG.com.

[4] Tejedor, Blanca; Casals, Miquel; Gangolells, Marta; Roca, Xavier (2017): Quantitative internal infrared thermography for determining in-situ thermal behaviour of façades. In Energy and Buildings 151, pp. 187-197. DOI: 10.1016/j.enbuild.2017.06.040.

[5] Albatici, Rossano; Tonelli, Arnaldo M.; Chiogna, Michela (2015): A comprehensive experimental approach for the validation of quantitative infrared thermography in the evaluation of building thermal transmittance. In Applied Energy 141, pp. 218-228. DOI: 10.1016/j.apenergy.2014.12.035.

[6] Estevam Schmiedt, J.; Cerra, D., Dahlke, D., Dill, S., Ge, N., Göttsche, J., Haas, A., Heiden, U., Israel, M., Kurz, F., Linkiewicz, M., Patel, D., Peichl, M., Plattner, S.,Pless, S., Schiricke, B., Schorn, C., Tiddens, A., Zhu, X. X. (Eds.) (2017): Remote sensing techniques for building models and energy performance studies of buildings. EBC Annex 71. Loughborough, UK, 26-28 April, 2017. Annex 71. First: Estevam Schmiedt, Jacob.

[7] Krawczyk, Jan; Mazur, Anna; Sasin, Tomasz; Stokłosa, Alicja (2015): Infrared building inspection with unmanned aerial vehicles. In PIL 240 (3), pp. 32-48. DOI: 10.5604/05096669.1194965.

[8] International Standard ISO 9869-1:2014(E), 1/8/2014: ISO 9869-1 Thermal insulation_building elements.

[9] A. laniro, G. Cardone (2010): Measurement of surface temperature and emissivity with stereo dual-wavelength IR thermography. In Taylor \& Francis 57, No. 18, pp. 1708-1715.

[10] Albatici, Rossano; Tonelli, Arnaldo M. (2010): Infrared thermovision technique for the assessment of thermal transmittance value of opaque building elements on site. In Energy and Buildings 42 (11), pp. 2177-2183. DOI: 10.1016/j.enbuild.2010.07.010.

[11] Howell, John R.; Siegel, Robert; Mengüç, M. Pinar (2015): Thermal radiation heat transfer. Sixth edition / John R. Howell, Robert Siegel, M. Pinar Menguc. Boca Raton: CRC Press.

[12] Hens, Hugo S. L. C. (2012): Building physics. Heat, air and moisture : fundamentals and engineering methods with examples and exercises / Hugo Hens. 2nd ed. Berlin: Ernst \& Sohn.

[13] An American National Standard (ASTM) E1862-97, June 1997: Standard Test Methods for Measuring and Compensating for Reflected Temparature Usinf Infrared Imaging Radiometers.

[14] Fokaides, Paris A.; Kalogirou, Soteris A. (2011): Application of infrared thermography for the determination of the overall heat transfer coefficient (U-Value) in building envelopes. In Applied Energy 88 (12), pp. 4358-4365. DOI: 10.1016/j.apenergy.2011.05.014 
[15] ISO/DIS 9869-2:2017(E), 2017: ISO 9869-2 Thermal Insulation-Building elements-In situ measurement of thermal resistance and thermal transittance.

[16] B. Blocken, T. Defraeye, D. Derome, J. Carmeliet (2009): High-resolution CFD simulations for forced convective heat transfer coefficients at the facade of a lowrise building. Building and Environment (2396-2412)

[17] Liu, Y.; Harris, D. J. (2007): Full-scale measurements of convective coefficient on external surface of a low-rise building in sheltered conditions. In Building and Environment 42 (7), pp. 2718-2736. DOI: 10.1016/j.buildenv.2006.07.013.

[18] Transmetra: TABLE OF EMISSIVITY OF VARIOUS SURFACES.PDF. Transmetra. Available online at www.transmetra.ch.

[19] Staeb, Christian: SU Emissionsgrad-Tabelle.xls.

[20] March 2008: Guide to the expression of uncertainty in measurement (GUM). Available online at www.bipm.org. 